\title{
Hydroxyurea and Necrotizing Fasciitis
}

\section{Busuttil DP*}

Consultant Haematologist, Mater Dei Hospital, Malta

*Corresponding author: Busuttil DP, Consultant Haematologist, Mater Dei Hospital, MSD2090, Malta, Tel: 79847688; Fax: (356)25454154; E-mail: david.p.busuttil@gov.mt

Received date: April 22, 2016, Accepted date: May 30, 2016, Published date: June 5, 2016

Copyright: ( 2016 Busuttil DP. This is an open-access article distributed under the terms of the Creative Commons Attribution License, which permits unrestricted use, distribution, and reproduction in any medium, provided the original author and source are credited.

Citation: Busuttil DP (2016) Hydroxyurea and Necrotizing Fasciitis. J Blood Lymph 6: 148. doi:10.4172/2165-7831.1000148

Keywords: Hydroxyurea; Myeloproliferative neoplasms; Essential thrombocythaemia; Necrotizing fasciitis

\section{Letter}

Cutaneous vasculitic toxicities including superficial vascular ulcerations and gangrene have occurred in patients with myeloproliferative neoplasms (MPNs) during therapy with hydroxyurea [1]. They are typically found in the perimalleolar region but also on the lower leg, heel, toes and occasionally the forearms, hands and face can be affected [2]. The pathogenesis is poorly understood. The macrocytosis which occurs in almost all patients on hydroxyurea may contribute as these macrocytes circulate poorly through the capillary network. In addition, hydroxyurea causes cumulative toxicity in the basal layer of the epidermis leading to cutaneous atrophy and impaired wound healing with dermal fibrosis and occasional fibrinoid thrombi [3]. Prior interferon therapy increases the risk of vasculitic toxicity. Necrotizing fasciitis is a toxicity that has never been associated with hydroxyurea before.

A 72 year old lady had been on hydroxyurea for essential thrombocythaemia of more than five years duration. The blood count was well controlled perioperatively on hydroxyurea when she underwent an elective hip replacement. One month later she was admitted with fever and confusion. As there was radiological evidence of pneumonia she was treated with piperacillin/tazobactam. There was no clinical improvement, so the hydroxyurea was discontinued but one week later she was noticed to have a tender, erythematous swelling in relation to the incision. An ultrasound revealed the presence of a large abscess. By then, progressive pancytopenia had set in with evidence of a disseminated intravascular coagulopathy. On clinical grounds, an infected haematoma was suspected but when surgical exploration of the site was performed, the subcutaneous and muscle tissue was found to be extensively necrotic in keeping with a diagnosis of necrotizing fasciitis. A debridement was performed but she lapsed into septic shock with acute renal failure and expired 24 hours later.
Necrotizing fasciitis is an uncommon condition caused by a mixture of aerobic and anaerobic organisms that cause necrosis of subcutaneous tissue. The affected tissues become red, hot and swollen resembling cellulitis and the area rapidly becomes gangrenous. Patients are acutely ill with sepsis and progress rapidly to multi-organ failure. The morbidity and mortality is high if not treated in its early stages, but there is difficulty in making an early diagnosis because of the initial paucity of cutaneous findings. When they do develop it is then difficult to differentiate from other superficial conditions like cellulitis [4]. It typically affects the extremities and follows surgery. Risk factors include age $>60$ years, renal failure, peripheral vascular disease, underlying malignancy and immunosuppressant drugs.

Awareness of the possibility of necrotizing fasciitis following hip replacements is warranted in patients with MPNs on hydroxyurea as the prognosis is poor without early aggressive treatment with antibiotics and surgical debridement. Cytoreduction of the elevated blood indices is important perioperatively to decrease the thrombotic and haemorrhagic risk of thrombocytosis, the latter adding to the already high risk inherent in hip replacement surgery. It may be advisable to consider anagrelide as an alternative platelet lowering agent perioperatively given that it is not cytotoxic and the possibility of post-operative necrotizing fasciitis would then be much reduced.

\section{References}

1. Stahl RL, Silber R (1985) Vasculitic leg ulcers in chronic myelogenic leukaemia. Am J Med 78: 869-72.

2. Antonioli E, Guglielmeli P, Pieri L, Finazzi M, Rumi E, et al. (2012) Hydroxyurea related toxicities in 341 patients with Ph negative MPN. Am J Hematol May 72: 317-21.

3. Natarajan S, Williamson D, Grey J, Harding KG, Cooper RA (2001) Healing of an MRSA-colonised, hydroxyurea induced leg ulcer with honey. J Dermatolog Treat 12: 33-6.

4. Navinan MR, Yudhishdran J, Kandeepan T, Kulatunga A (2014) Necrotizing fasciitis- a diagnostic dilemma: two case reports. Journal of Medical Case reports 8: 229. 